\section{U.S. DEPARTMENT OF ENERCY}

\section{Office of}

ENERGY EFFICIENCY \& RENEWABLE ENERGY

\title{
Multizone Residential HVAC Modeling
}

November 2020 


\section{Disclaimer}

This work was prepared as an account of work sponsored by an agency of the United States Government. Neither the United States Government nor any agency thereof, nor any of their employees, nor any of their contractors, subcontractors or their employees, makes any warranty, express or implied, or assumes any legal liability or responsibility for the accuracy, completeness, or any third party's use or the results of such use of any information, apparatus, product, or process disclosed, or represents that its use would not infringe privately owned rights. Reference herein to any specific commercial product, process, or service by trade name, trademark, manufacturer, or otherwise, does not necessarily constitute or imply its endorsement, recommendation, or favoring by the United States Government or any agency thereof or its contractors or subcontractors. The views and opinions of authors expressed herein do not necessarily state or reflect those of the United States Government or any agency thereof, its contractors or subcontractors.

Available electronically at Office of Scientific and Technical Information website (osti.gov)

Available for a processing fee to U.S. Department of Energy

and its contractors, in paper, from:

U.S. Department of Energy

Office of Scientific and Technical Information

P.O. Box 62

Oak Ridge, TN 37831-0062

OSTI osti.gov

Phone: 865.576 .8401

Fax: 865.576.5728

Email: reports@osti.gov

Available for sale to the public, in paper, from:

U.S. Department of Commerce

National Technical Information Service

5301 Shawnee Road

Alexandria, VA 22312

NTIS ntis.gov

Phone: 800.553 .6847 or 703.605 .6000

Fax: 703.605.6900

Email: orders@ntis.gov 


\title{
Multizone Residential HVAC Modeling
}

\author{
Prepared by: \\ Andrew Poerschke, IBACOS \\ Prepared for: \\ Building Technologies Office \\ Office of Energy Efficiency and Renewable Energy \\ U.S. Department of Energy
}

November 2020

NREL Technical Monitors: Stacey Rothgeb and Conor Dennehy 


\section{Acknowledgments}

The report author would like to acknowledge input and feedback from Jason DeGraw, one of the EnergyPlus ${ }^{\circledR}$ developers from Oak Ridge National Laboratory.

This report was funded by the Residential Buildings Integration program within the U.S. Department of Energy, Office of Energy Efficiency and Renewable Energy, Building Technologies Office.

\section{Table of Contents}

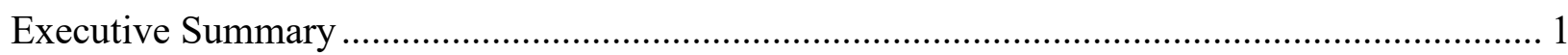

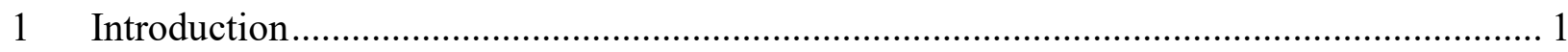

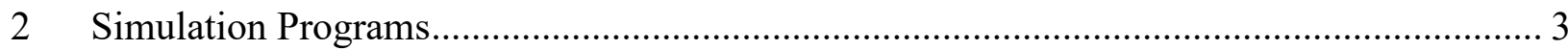

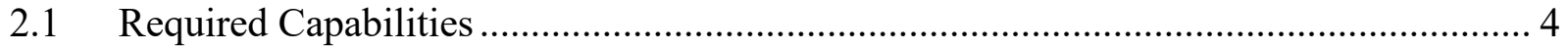

3 EnergyPlus Model Features and Associated Gaps..................................................... 7

3.1 Thermal Performance of the Building Envelope and Internal Gains ........................... 7

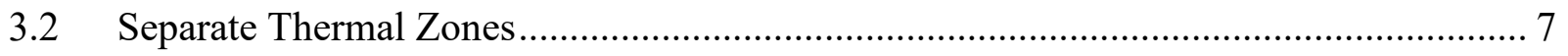

3.3 AHU, Duct System, and Room Airflow Models .................................................... 7

3.4 Model Supply and Return System Airflows ….................................................... 8

3.5 Model Fan With Performance Curve and Variable Speed Fan Control........................ 8

3.6 Variable Loss Coefficient Linkage Components ...................................................... 9

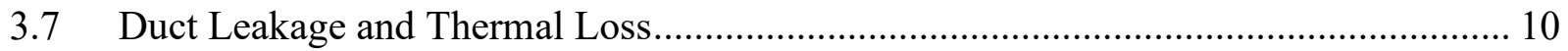

3.8 Simulate Thermostat Control and System Cycling for Multiple Independent Zones .... 10

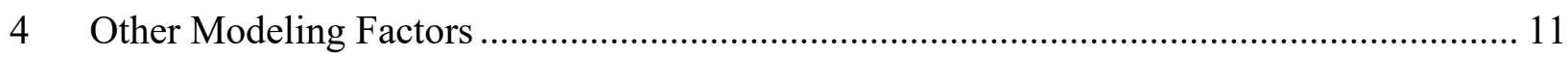

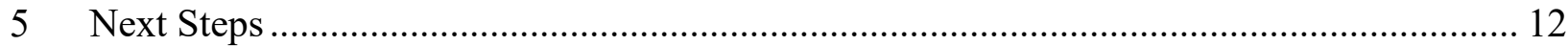

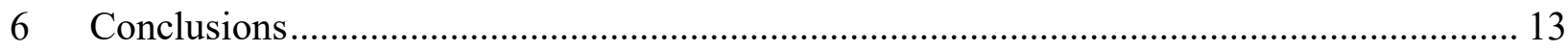

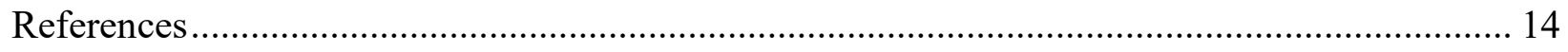




\section{Executive Summary}

New and affordable heating, ventilating, and air conditioning (HVAC) technologies can improve energy efficiency and the grid responsiveness of buildings, while improving occupant comfort. Computer simulations are a powerful tool to speed up the development of new products and technologies. This paper identifies building energy modeling programs that have the capabilities to emulate real-world HVAC performance and comfort. Of the programs, EnergyPlus ${ }^{\circledR}$ is selected for a deeper consideration of its capabilities and feature gaps. Several gaps and resolutions are identified.

\section{Introduction}

Buildings are increasingly viewed as electric grid assets; new technologies will be required to maintain occupant comfort while optimizing demand flexibility for the grid. The primary goals of building space-conditioning systems are to provide occupant comfort and health as well as improve building durability. Any electric demand response approach must account, at minimum, for occupant comfort and provide an effective tradeoff between load management, cost savings, and homeowner desires.

One possible mechanism for achieving a better balance between comfort and load flexibility could exist in next-generation zoning technologies for space conditioning, including affordable bypass-free and room-by-room zoning. These technologies have the potential to maintain higher levels of comfort while providing grid operators with the capacity for larger electric load reductions. Control algorithms could decide which zones are prioritized for space conditioning based on occupant input and sensor data. Initial studies have found that $14 \%-26 \%$ of spaceconditioning energy is wasted by conditioning unoccupied zones (Meyers 2010; Brown 2007). Due to uneven load distributions within a building over time and the limitations of a single, centrally located thermostat, some portions of the building may be over-conditioned and wasting energy, while others are under-conditioned and occupant comfort suffers. Inadequate design integration between the architecture and the HVAC system, along with poor installation quality and unbalanced airflows, contribute to thermal imbalances and further increase the likelihood of wasted energy and increased peak demand.

Next-generation forced air zoning technologies include systems of sensors, actuators, and models that can automatically and affordably provide effective room-level zoning to optimize occupant comfort. This can be accomplished through the use of control dampers located in the air distribution pathway for each room. Traditionally this is done using an electronically controlled damper located at the entrance to each zone's supply duct run. Complex installation and expensive components increase the cost of these systems beyond what a large-volume builder will consider. More affordable products on the market today accomplish this through the use of electronically adjustable registers, which communicate with a central hub. Controlling airflow at the register comes with the drawback that duct leakage may increase. 
While the promise of next-generation zoning technologies is significant, current research and development efforts have been slow and inadequate to meet market needs. One way to speed up the development of this technology is to utilize building physics simulation to rapidly test and evaluate potential control strategies to meet demand more precisely within the rooms and zones of a building over time. Building simulation programs often use weather (Typical Meteorological Year) data to simulate thermal and moisture loads and operation of the HVAC equipment. Given sufficient accuracy and time resolution, these programs can also be used to simulate the cyclic operation of space-conditioning equipment and controls.

This report will evaluate several building physics modeling tools to determine which are best suited for developing next-generation zoning technology. These modeling tools will be evaluated for their ability to predict room-level thermal loads, HVAC system operation, temperature and comfort predictions, and scalability. Any gaps in the existing tools will be identified and a path forward will be discussed. 


\section{Simulation Programs}

Simulation tools can model building energy dynamics as well as HVAC operation and natural and forced airflows. These programs employ calculation engines that are driven by time-varying weather data and occupant "usage and operation" schedules. The programs evaluated in this paper are listed in Table 1:

Table 1. Comparison of Modeling Data

\begin{tabular}{|c|c|c|c|c|}
\hline Program & Capabilities & License & Usability & Resource \\
\hline CONTAM & Multizone airflow & Public domain & $\begin{array}{l}\text { Basic interface } \\
\text { for drawing and } \\
\text { configuring } \\
\text { models }\end{array}$ & $\begin{array}{l}\frac{\text { https://www.nist.gov/se }}{\text { rvices- }} \\
\frac{\text { resources/software/con }}{\text { tam }}\end{array}$ \\
\hline COMIS & Multizone airflow & Open source & $\begin{array}{l}\text { No longer } \\
\text { updated or } \\
\text { maintained }\end{array}$ & $\frac{\text { https://www.buildup.eu/ }}{\underline{\text { en/node/7541 }}}$ \\
\hline EnergyPlus & $\begin{array}{l}\text { Whole-building } \\
\text { energy and } \\
\text { multizone airflow }\end{array}$ & Open source & $\begin{array}{l}\text { Continuously } \\
\text { updated and } \\
\text { improved; widely } \\
\text { used by } \\
\text { researchers and } \\
\text { practitioners }\end{array}$ & https://energyplus.net/ \\
\hline ESP-r & $\begin{array}{l}\text { Whole-building } \\
\text { energy and } \\
\text { multizone airflow }\end{array}$ & Open source & $\begin{array}{l}\text { Geared toward } \\
\text { researchers with } \\
\text { limited user } \\
\text { interface and } \\
\text { modeling aids }\end{array}$ & $\frac{\frac{\text { https://www.strath.ac.u }}{\text { k/research/energysyste }}}{\frac{\text { msresearchunit/applica }}{\underline{\text { tions/esp-r/ }}}}$ \\
\hline TRNSYS & $\begin{array}{l}\text { Whole-building } \\
\text { energy, can be } \\
\text { coupled with other } \\
\text { tools for airflow } \\
\text { simulation }\end{array}$ & Closed source & $\begin{array}{c}\text { Integrated user } \\
\text { interface (UI) and } \\
\text { simulation control } \\
\text { tools }\end{array}$ & http://www.trnsys.com/ \\
\hline Modelica & $\begin{array}{c}\text { Energy and } \\
\text { multizone airflow } \\
\text { (multiple physics } \\
\text { domains) }\end{array}$ & $\begin{array}{l}\text { Open-source } \\
\text { language, } \\
\text { proprietary } \\
\text { solvers }\end{array}$ & $\begin{array}{l}\text { Requires detailed } \\
\text { knowledge of the } \\
\text { Modelica } \\
\text { environment }\end{array}$ & $\frac{\text { https://simulationresear }}{\underline{\text { ch.lbl.gov/modelica/ }}}$ \\
\hline WUFI Plus & $\begin{array}{l}\text { Whole-building } \\
\text { energy and } \\
\text { hydrothermal } \\
\text { performance; can } \\
\text { be coupled with } \\
\text { other tools to } \\
\text { simulate HVAC } \\
\text { operation }\end{array}$ & Closed source & $\begin{array}{l}\text { Integrated UI and } \\
\text { simulation control } \\
\text { tools }\end{array}$ & $\frac{\text { https://wufi.de/en/softw }}{\text { are/wufi-plus/ }}$ \\
\hline
\end{tabular}


A more exhaustive list maintained by the International Building Performance Simulation Association in the United States can be found at: https:/www.buildingenergysoftwaretools.com/. Each of these building simulation programs has a specific set of capabilities, many of which overlap with each other, while other capabilities are unique to each program.

Some of these simulation programs have a complete set of capabilities to model both building energy and airflow systems; however, some have a more specific use. The practice of cosimulation can link different programs at different levels. At the lowest level, software code can be directly integrated into the compiled executable of another program. An example of this is the integration of the Airflow Network (AFN) model as an extension of the core capabilities of the EnergyPlus engine. At a middle level, data are exchanged between separate simulations at runtime. At the highest level, linkage tools such as the Building Controls Virtual Test Bed can coordinate data exchange between different running simulation software. As the linkage becomes more abstract, there are negative impacts on accuracy and performance. Despite this, cosimulation tools can be helpful as a starting point in simulating new HVAC and control systems.

\subsection{Required Capabilities}

Emulating the real-world operation of multizone-controlled HVAC systems requires the following key capabilities in a modeling tool:

- Detailed building envelope and internal gains thermal performance (including the location and associated zone of building components and internal gains)

- Separate thermal zones

- Air handler unit (AHU), duct system, and room predictive airflow model

○ Supply and return system airflows

- Fan with performance curve and variable speed fan control

○ Variable loss coefficient damper components

○ Duct leakage

○ Duct thermal losses

- Thermostat control and system cycling for multiple independent zones.

In addition, the HVAC equipment and duct system must be sized and designed, typically using a dedicated design software. Air Conditioning Contractors of America publishes a set of manuals for designing residential HVAC systems. While not a focus of this paper, correctly sizing equipment and duct systems is an important step in developing and accurately simulating the performance of a real-world HVAC system. The output of the HVAC sizing and design steps must then be translated as an input to the building energy modeling software.

The following matrix indicates the capabilities of each software program related to emulating the real-world operation of multizone-controlled HVAC systems. 
Table 2. Modeling Tool Matrix

\begin{tabular}{|c|c|c|c|c|}
\hline Program & $\begin{array}{c}\text { Building } \\
\text { Thermal } \\
\text { Simulation }\end{array}$ & $\begin{array}{c}\text { Separate } \\
\text { Thermal } \\
\text { Zones }\end{array}$ & $\begin{array}{c}\text { AHU, Duct } \\
\text { System, and } \\
\text { Room Airflow } \\
\text { Model }\end{array}$ & $\begin{array}{c}\text { Thermostat } \\
\text { Control }\end{array}$ \\
\hline CONTAM & Partial & $\mathrm{X}$ & $\mathrm{X}$ & $\mathrm{X}$ \\
\hline COMIS & $\mathrm{X}$ & $\mathrm{X}$ & $\mathrm{X}$ & $\mathrm{X}$ \\
\hline EnergyPlus & $\mathrm{X}$ & $\mathrm{X}$ & $\mathrm{X}$ & $\mathrm{X}$ \\
\hline ESP-r & $\mathrm{X}$ & $\mathrm{X}$ & $\mathrm{Co-sim}$ & $\mathrm{X}$ \\
\hline TRNSYS & $\mathrm{X}$ & $\mathrm{X}$ & $\mathrm{X}$ & $\mathrm{X}$ \\
\hline Modelica & $\mathrm{X}$ & $\mathrm{X}$ & Co-sim & $\mathrm{X}$ \\
\hline WUFI Plus & & & & \\
\hline
\end{tabular}

In addition to the above criteria, factors that impact the software choice for modeling multizone HVAC system performance include software maturity, North American user base, and opensource code.

Based on these criteria, EnergyPlus is the ideal simulation tool for this study because it has an integrated building thermal model and an AFN model. EnergyPlus is widely used in the building simulation community, so any improvements to this engine can be leveraged by several thirdparty software programs. EnergyPlus has all the required capabilities mentioned in this paper, as well as the ability to quickly get a complete residential simulation up and running with frontends such as BEopt ${ }^{\mathrm{TM}}$ and OpenStudio ${ }^{\circledR}$. The current EnergyPlus version is 9.3, and the conclusions in this document are based on this version.

EnergyPlus has been under development for decades (EnergyPlus 2020). The core engine was developed with funding from the U.S. Department of Energy (DOE) and is open source and freely available to the public. It is easily integrated into third-party applications. Multiple commercial companies have developed front-end interfaces for creating and running EnergyPlus models.

EnergyPlus's AFN uses a network of linkages and nodes to simulate air movement within a building and the air distribution system ( $\mathrm{Gu}$ 2007). Each linkage connects to exactly two nodes. Nodes may have any number of linkages attached to them. The solver uses a conservation of mass algorithm to predict the airflow through each linkage in the network.

Figure 1 is a representation of a portion of an AFN with parameters and values. 


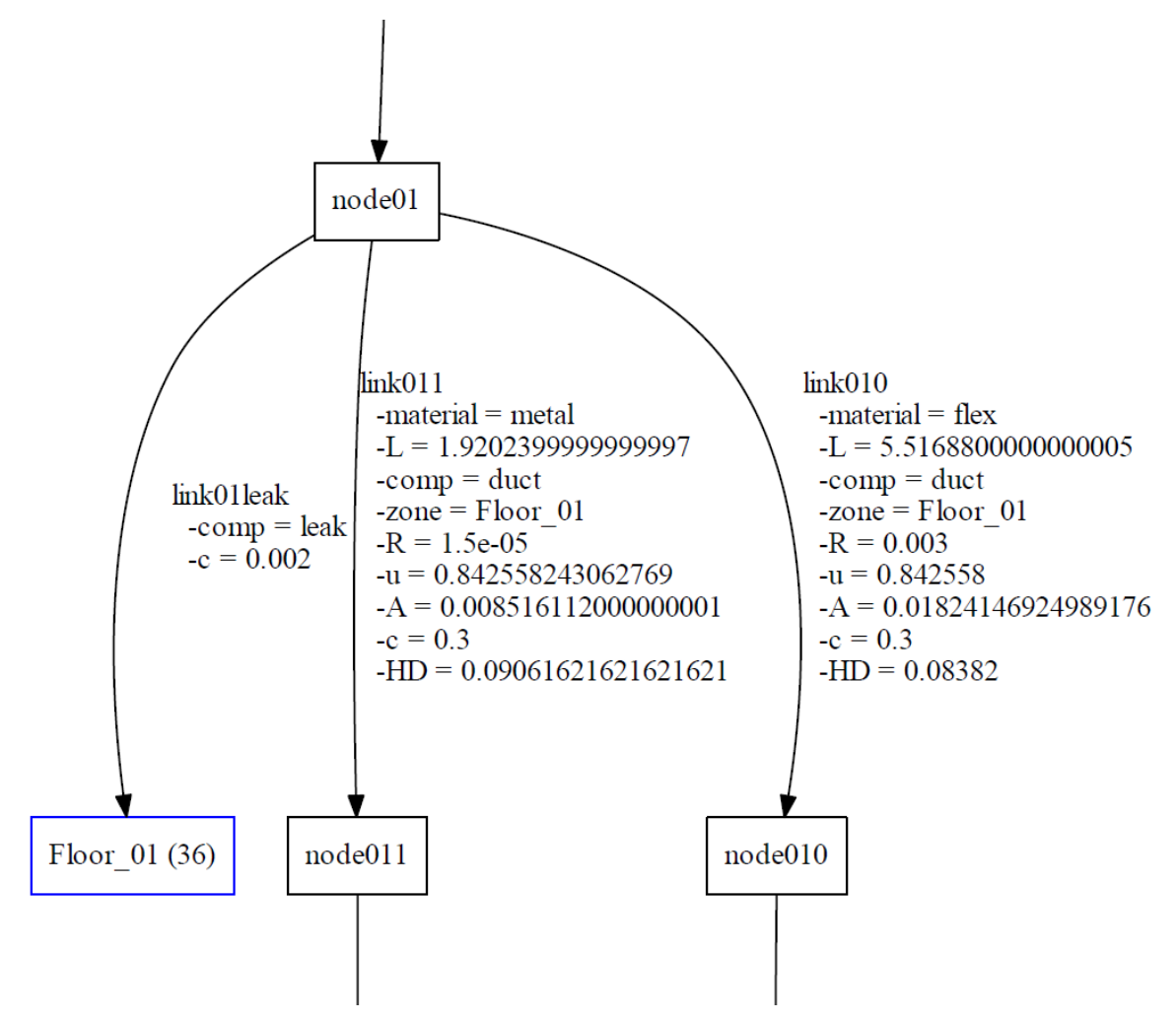

Figure 1. Example of a node and linkage with parameters

Figure from IBACOS

AFN is capable of simulating both controlled (forced) airflows and uncontrolled airflows from sources such as infiltration and convective mixing. For the purposes outlined in this report, the primary questions that need to be answered require a robust model for controlled airflow. 


\section{EnergyPlus Model Features and Associated Gaps}

The required modeling capabilities are discussed further in this section. For each capability, the current features of EnergyPlus and AFN modeling are presented (EnergyPlus 2020) as well as any technical or performance gaps and areas of needed improvement.

\subsection{Thermal Performance of the Building Envelope and Internal Gains}

It is critical to correctly represent the external and internal loads on a building and its rooms to accurately evaluate the effectiveness of a specific HVAC control strategy to meet those loads. EnergyPlus can simulate the relevant loads, as well as internal occupant schedules and thermal gains. Existing front-end programs such as BEopt can automatically set-up typical residential use schedules and internal gains following the Building America Simulation Protocol (Wilson et al. 2014). Additionally, the EnergyPlus simulation engine must account for the thermal mass of the room air, so the room temperature can accurately be predicted as the space-conditioning system cycles on and off. Currently, EnergyPlus accounts for the moist air thermal mass in a zone, and has an adjustable multiplier if additional mass is needed to stabilize the model or better represent objects in a typical home (e.g., furniture, appliances) that could impact the thermal mass of the air.

Through additional effort, the single-zone model from BEopt can be split into multiple zones suitable for evaluating zoned HVAC controls. This effort requires the user to reallocate block loads and gains to each new zone. Building geometry and wall constructions must also be modified. No existing user interface exists to perform these tasks. However, a researcher skilled with 3D modeling software and scripting can automate this task given assumptions about where loads should be distributed.

\subsection{Separate Thermal Zones}

Simulating discrete thermal zones is necessary for simulating a control system that can individually condition each room. EnergyPlus is capable of simulating multiple thermal zones in a building. The coupled EnergyPlus and AFN solvers can predict the zone air temperature and humidity necessary to evaluate control strategies.

Existing residential modeling front-end programs for EnergyPlus, such as BEopt, are primarily focused on quickly setting up a model with a single conditioned zone. Setting up multizone models requires manually modifying input files, or stitching together data from multiple sources, such as BEopt and a computer aid design program (Beach et al. 2017). Although this process is viable for a researcher looking at a limited number of house cases, it is not scalable for a design professional.

\subsection{AHU, Duct System, and Room Airflow Models}

One shortcoming of the existing AFN implementation is that there are certain EnergyPlus air loop requirements that may not be required in a residential setting. For example, each supply 
zone requires a direct return link from the zone to the air handler to satisfy the EnergyPlus air loop requirements (i.e., every supplied room requires a dedicated return). Common practice in residential HVAC systems is to use open hallways and room air transfers as the return path, and not provide a direct duct linkage from each room to a return plenum. A viable work-around exists by specifying the direct return linkage as a very high loss component, and connecting the return cavities (e.g., halls, rooms) to a low-resistance room transfer. A central return plenum then connects the return cavities to the AHU equipment. Although this approach is acceptable, it would be more efficient to include return pathways that directly simulate a typical residential system.

\subsection{Model Supply and Return System Airflows}

Simulating the supply and return air pathway components is a key capability of AFN modeling. Given a complete and closed network of linkages and nodes, the airflow through each linkage and pressure at each node can be computed using numeric methods. The airflow to each zone is then accounted for in the zone's energy balance.

Assembling a complete supply and return model requires detailed knowledge of the design specifics. Real-world systems have uncertainty in the exact installation geometry and installation quality, which need to be accounted for to understand how the modeled system and controls react to real-world inconsistencies.

\subsection{Model Fan With Performance Curve and Variable Speed Fan Control}

Accurately modeling fan performance is critical to determine if the control strategy is maintaining flow and static pressure within the limits of the AHU fan. The current fan models that are implemented in AFN are Fan:OnOff, Fan:ConstantVolume, Fan:VariableVolume, and Fan:SystemModel. These fan models assume that the fan is hitting its airflow target, regardless of the duct system's static pressure. The airflow from a typical residential constant torque electronically commutated motor drops off as the static pressure increases. Modeling this phenomenon is critical to accurately simulate airflow, pressure, and energy performance as control dampers open and close. Additionally, accurately modeling system static pressure can provide designers and practitioners guidance on overall system durability as well as a more accurate representation of motor energy use.

Figure 2 shows the intersection of a fan curve and duct system curve. As the duct system curve loss increases or decreases, the curve intersection, or operating point, will adjust accordingly. A real-world zone controller can account for the change in pressure and airflow in its control algorithm. To emulate these control algorithms in a building simulation, this effect needs to be simulated. 


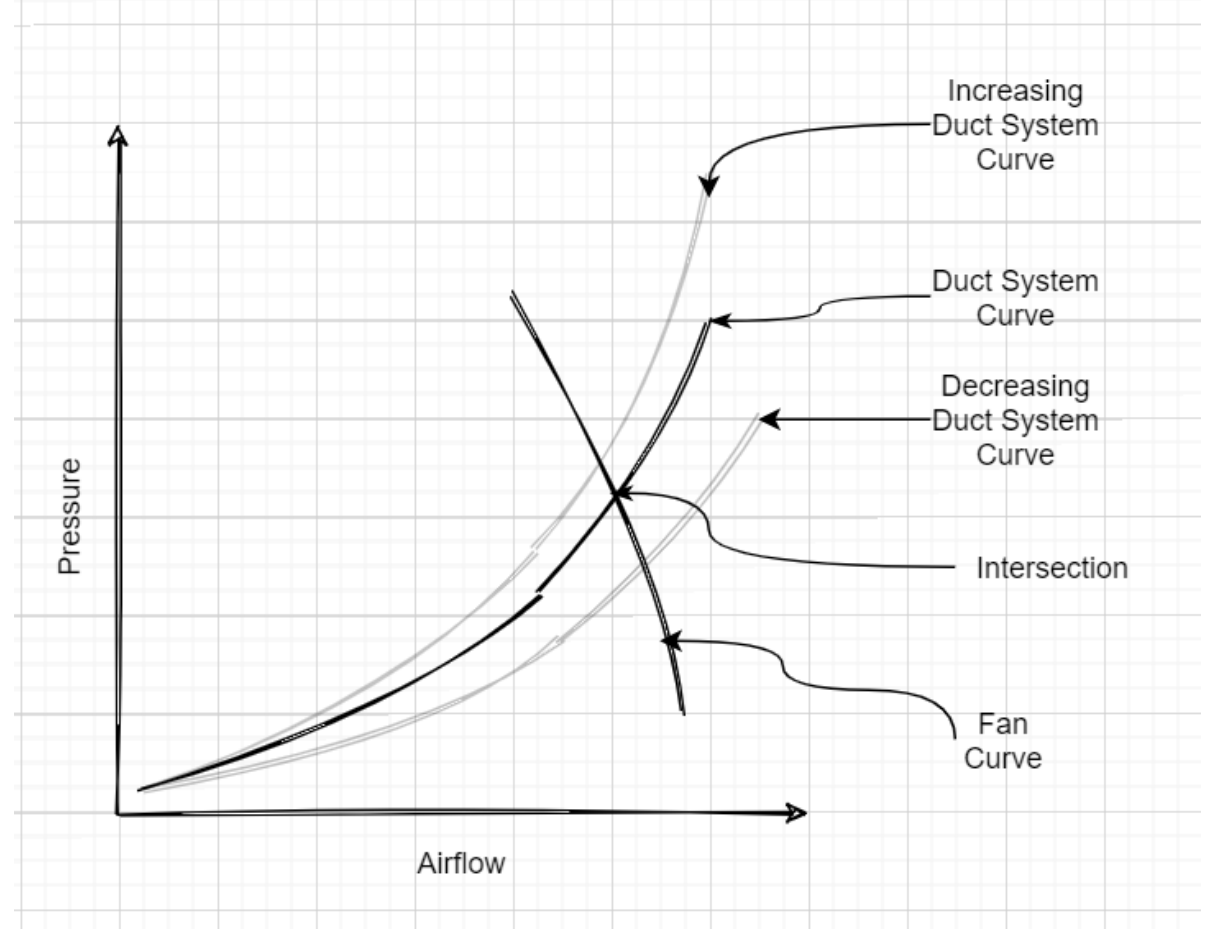

Figure 2. Example fan performance curve

Figure from IBACOS

Including a fan curve model would be critical to simulate real-world control systems and is currently not an active feature of EnergyPlus or AFN. Enabling and testing this capability would be a significant effort for the EnergyPlus developers, as it would impact multiple assumptions in the engine. Due to limitations imposed by the core EnergyPlus code and its HVAC system solver, there is no easy path to include a pressure performance curve as part of AFN. Significant testing would be required to make sure other portions of the code are not adversely affected. Utilizing a fan performance curve is not a frequent task of energy modeling practitioners, though with the recent emphasis on AHU fan efficiency, especially in residential construction, this may change.

\subsection{Variable Loss Coefficient Linkage Components}

Simulating zone damper control will require the ability to modify the loss coefficient for an AFN linkage component. Currently this is not possible within the software, largely due to lack of industry need. Implementing a "schedule" to address an existing linkage component would let an energy management system modify loss coefficients between timesteps. This effort would be straightforward and require minimal developer time. A more robust physical damper model could also be implemented as a linkage object type but would require significant testing to ensure stable behavior. 


\subsection{Duct Leakage and Thermal Loss}

AFN has two mechanisms for simulating duct leakage, the generic Leak and Leakage Ratio. Either of these is sufficient for predicting the leakage through a duct system's components.

Duct-linkage objects account for thermal loss using an average U-value. Using a simple conduction model, the heat loss or gain to the surrounding air through each segment of duct can be determined. The delivered energy into a room is determined by the duct air temperature at the end of the run. If significant energy is lost along the length of a duct, then room air temperature and comfort will be affected.

A multizone HVAC system can respond to insufficient delivered energy due to thermal losses or gains in ways a conventional air distribution system cannot. Therefore, it is important to accurately capture this effect in the simulation model so that the benefit is shown. The currently implemented model in EnergyPlus has been validated as accurate for predicting supply air temperatures ( $\mathrm{Gu}$ 2007).

One limitation of the currently implemented model is that thermal capacitance of the duct material is not modeled. During system on/off cycles, the duct and air within the duct are assumed to reach steady state immediately. For long duration cycles, this is not a significant factor. However, in real-world situations, if the HVAC system is operating at part load with frequent on/off cycles, then the duct temperature and thermal loss will never reach steady state, and longer duct runs will ultimately deliver less energy. While modeling thermal capacitance would improve the accuracy of modeling various duct system designs, there is currently no planned timeline for including this functionality in the EnergyPlus code. The current implementation is acceptable as long as accurately simulating short cycles is not desired. Additionally, implementing an accurate model would significantly slow down simulation times.

\subsection{Simulate Thermostat Control and System Cycling for Multiple Independent Zones}

In typical usage, EnergyPlus does not simulate the discrete on/off cycles of air handling equipment, but rather predicts the percentage of the timestep that equipment would operate. To emulate real-world control strategies, the HVAC equipment must be cycled according to thermostatic control. To accurately capture cyclic behavior, short simulation timesteps (on the order of 1-minute) are required. EnergyPlus has an on/off thermostat model with a user-specified deadband that can be used to simulate cycling behavior. Alternately, a thermostat model can be written using the EnergyPlus runtime language. Recent releases of EnergyPlus include a Python application program interface (API), which can open the door to new control mechanisms using the open-source and widely recognized Python programming language. The Python API is a new feature that is still under active development by the EnergyPlus development team. 


\section{Other Modeling Factors}

An EnergyPlus simulation requires several components to exist in an input file in order to run. These components are part of typical commercial building HVAC systems and may not be relevant to single-family residential construction or residential space-conditioning equipment. Properly setting up and including these components is cumbersome and poses additional overhead if the user is interested in modeling the simpler equipment and air loops of a residential system. Work is under way by the EnergyPlus developers to modularize the core functionality of EnergyPlus, so that an entire model is not required to run a simulation with a subcomponent. This effort could ease the setup requirements for researchers and practitioners and make individual model components available to a wider range of industry users.

Setting up the inputs required for running an EnergyPlus model currently either requires significant time and expertise, or the use of a third-party user interface (UI). There are currently several UIs for setting up and running an EnergyPlus simulation. The most current and featurerich interface is the OpenStudio Application, ${ }^{1}$ which was developed in collaboration with several of DOE's national laboratories. As of version 2.5.0, the AFN modeling functionality has been added to OpenStudio.

The OpenStudio Application is currently undergoing a transition in ownership from DOE's Building Technologies Office to private industry and third parties. The intention is that these third parties can better update and manage UIs for publicly sponsored and standardized calculation engines.

Setting up a full AFN model with the air distribution ductwork can take significant configuration time. Every segment of duct must be specified, along with the space it runs through. This effort means a typical practitioner may resist performing AFN modeling, though it can still bring significant value to researchers and product developers. Industry could develop tools to automate the setup and creation of airflow models, reducing this barrier to entry.

Scaling a single building simulation to a wider housing stock and to climate zones improves the validity of any conclusions. The National Renewable Energy Laboratory has a project called ResStock ${ }^{\mathrm{TM}}$, which is a framework for scaling building models across construction types, climates, and code requirements. A sophisticated user could set up a framework to translate a prototype house or set of prototype houses across different climate zones and code levels, and automatically scale the duct design based on various house loads. This is another area where improved UIs and software could make these processes accessible to a wider audience and better leverage the powerful capabilities of the underlying simulation engines. As an example, an HVAC design practitioner could evaluate the impact of design changes on a lot-level basis for an entire community or set of communities across many climate zones. This kind of capability could further optimize future grid-interactive communities.

\footnotetext{
${ }^{1}$ For more information, see https:/www.openstudio.net/new-future-for-openstudio-application.
} 


\section{Next Steps}

A few key developments would provide the necessary functionality for EnergyPlus to accurately model residential multizone HVAC systems. Modularizing the EnergyPlus code and components by streamlining the inputs for residential versus commercial systems would make it easier for third-party developers and users to make best use of the established codebase. Although EnergyPlus is a highly capable software, to simulate even the simplest of structures, several required components must be included in the input file in a specific order. This makes it difficult to use a subcomponent or module independent of the rest of the simulation engine. Existing efforts to refactor and modularize the EnergyPlus code should be supported and continued until this work is done.

Bridging the two identified gaps - lack of a fan performance curve and variable loss dampersshould be considered by the EnergyPlus development team. Efforts are already underway to tackle these changes. The variable loss damper has a straightforward path to implementation. Modeling a fan performance curve will require the developers to thoroughly define the impact to multiple areas of the calculation engine and agree on the best path to implementation. 


\section{Conclusions}

This document evaluated software for modeling the performance of buildings, specifically HVAC air distribution systems. Based on a comparison of each modeling program, EnergyPlus was chosen as the candidate to be further evaluated and to identify any gaps in capabilities in this context.

Fundamentally, EnergyPlus and AFN have the capabilities to simulate both a home as well as detailed HVAC equipment and duct system operation. Several gaps exist to accurately simulate the operation of a multiroom zone controller. These gaps include the ability to model a fan with a flow performance curve and to vary the loss coefficient as zone dampers open and close. The core EnergyPlus architecture can accommodate these components; however, work is required by the developers to enable their functionality.

If these gaps are overcome, EnergyPlus could be leveraged by researchers to develop the next generation of residential HVAC zoning technology, which could improve the adoption of demand response programs and grid-interactive buildings, while optimizing occupant comfort and building energy efficiency. 


\section{References}

Beach, R., B. Dickson, A. Grisolia, A. Poerschke, and A. Rapport. 2017. A Plug-and-Play Duct System Evaluation. Prepared by IBACOS on behalf of the U.S. Department of Energy. https://www.osti.gov/servlets/purl/1394730.

Brown, CA. 2007. "Multizone register controlled residential heating: Optimized for energy use and comfort." MS Thesis, U.C. Berkeley. https://escholarship.org/uc/item/5j1996rn.

EnergyPlus. 2020. “EnergyPlus Documentation.” energyplus.net/documentation.

Gu, L. 2007. "Airflow Network Modeling in EnergyPlus.” Proceedings of Building Simulation. FSEC-PF-428-07.

https://www.researchgate.net/profile/Lixing_Gu/publication/252575304_Airflow_network_mode ling_in energyplus/links/5666dc2c08ae9d6f12dce1b7.pdf.

Meyers, R.J., E.D. Williams, and H.S. Matthews. 2010. "Scoping the potential of monitoring and control technologies to reduce energy use in homes." Energy and Buildings 42, 563-569. https://www.sciencedirect.com/science/article/pii/S0378778809002758.

Wilson, E., C. Engebrecht Metzger, S. Horowitz, and R. Hendron. 2014. Building America House Simulation Protocols. NREL/TP-5500-60988.

https://www.nrel.gov/docs/fy14osti/60988.pdf. 
